\title{
HIỆU QUẢ CAN THIÊPP BỔ SUNG VITAMIN D CẢI THIỆN TỶ LỂ NHIỂM KHUẨN HỐ HẤP Ở TRẺ DƯớI 5 TUỔI TẠI AN LÃO, HẢI PHÒNG NĂM 2017
}

\author{
Nguyễn Thị Ngọc Yến*, Vũ Thị Thủy*, Đinh Văn Thức**
}

\section{TÓM TẮT}

Mục tiêu. Nghiên cứu nhằm đánh giá hiệu quả cải thiện nồng độ vitamin $D$ và tỷ lệ nhiễm khuẩn hô hấp cấp bằng bổ sung vitamin $\mathrm{D}$ liểu 500 IU hàng ngày trong thời gian 1 năm. Đối tượng và phương pháp. Đối tượng gồm 164 trẻ chia thành 2 nhóm can thiệp và nhóm chứng mỗi nhóm 82 đối tượng. Phương pháp nghiên cứu can thiệp cộng đồng, đánh giá trước sau có đối chứng. Kết quả và kết luận. Sau can thiêp nồng độ vitamin $D$ trung bình của nhóm can thiệp tăng thêm $5,54 \mathrm{ng} / \mathrm{ml}$ so với của nhóm chứng là $1,38 \mathrm{ng} / \mathrm{ml}$, nồng độ vitamin $\mathrm{D}$ trung bình tăng thêm là $4,16 \mathrm{ng} / \mathrm{ml}$. Can thiệp vitamin $\mathrm{D}$ đã làm giảm tỷ lệ nhiễm khuẩn hô hấp ở nhóm can thiệp được 37,2\% so với nhóm chứng là $20,7 \%$, tỷ lệ nhiểm khuẩn hô hấp của nhóm can thiệp giảm hơn nhóm chứng là $22,7 \%$.

Tứ khóa. Nghiên cứu can thiệp, hiệu quả, vitamin D, nhiễm khuẩn hô hấp.

\section{SUMMARY}

THE EFFICACY OF VITAMIN D SUPPLEMENTATION FOR CHILDREN UNDER 5 TO IMPROVE THE INCIDENCE OF ACUTE RESPIRATORY INFECTION IN AN LAO, HAI PHONG IN 2017

Objective. The study was carried out to evaluate the efficacy of 500 IU vitamin D supplementation daily for children under 5 to improve the the incidence of acute respiratory infection in An Lao, Hai Phong in 2017 during one year. Subjects and Methods. Subjects included 164 under 5 children divided into 2 groups: intervention and control group. Method was a community intervention controlled trial, compared before and after the entervention. Results and conclusions. After the intervention, mean vitamin D of intervention group increased $5.54 \mathrm{ng} / \mathrm{ml}$ higher than that of control group $1.38 \mathrm{ng} / \mathrm{ml}$, mean vitamin D difference between group was $4.16 \mathrm{ng} / \mathrm{ml}$. Vitamin D supplementation reduced $37.4 \%$ in the intervention group and $14.7 \%$ in the control group, and incidence difference between 2 groups was $22,7 \%$.

Keywords. Intervention study, efficacy, vitmain $D$, acute respiration infection.

\section{I. ĐĂT VẤN ĐỀ}

Từ năm 1983 TCYTTG đã xây dựng chương

*Bệnh viện Trẻ em Hải Phòng

**Trường Đai hoc Y Dước Hải Phòng

Chịu trách nhiệm chính: Nguyễn Thị Ngọc Yến

Email: bsyenbvte@gmail.com

Ngày nhận bài: 22.6.2021

Ngày phản biên khoa hoc: 17.8.2021

Ngày duyệt bài: 23.8.2021 trình phòng chống nhiễm khuẩn hô hấp cấp tính (chương trình ARI), áp dụng ở Việt Nam vào năm 1984 đã là làm tỷ lệ mắc và tử vong đáng kể bệnh này tuy nhiên NKHHC vẫn là bệnh có tỷ lệ mắc và tử vong cao ở lứa tuổi này[2]. Indonesia, Ấn Độ, Nigeria, Pakistan và Trung Quốc đã chiếm 54\% trong số 138 triệu viêm phổi trên toàn câu vào năm 2015 [4]. Theo Adebola E. Orimadegun và CS [3], có 1.071 triệu trẻ 1-59 tháng ở châu Phi chết vì viêm phổi, chiếm 14,1\% tử vong do tất cả các nguyên nhân.

Từ năm 2007, sau khi Holick FM [9] công bố dịch thiếu hụt vitamin $D$ và vai trò của nó trong nhiều bệnh nhất là trong việc cải thiện tỷ lệ bệnh nhiễm khuẩn hô hấp cấp đã có nhiều nghiển cứu can thiệp được tiến hành. Tuy nhiên theo Giuseppe Saggesse và CS [5] trong đông thuận của Hội Nhi khoa Italia năm 2018 cho thấy qua nghiên cứu gộp các thử nghiệm lâm sàng, nghiên cứu quan sát trên thế giới còn có các ý kiến trái chiêu nhau. Cũng theo Giustina $A$ và $C S$ [6] về đồng thuận Quốc tế lần thứ 2 về những những vấn đề còn chưa thống nhất về vitamin $D$. Theo các đồng thuận này thì tác dụng của vitamin $D$ làm giảm tỷ lệ mắc $N K H H C$ và làm giảm mức độ nặng của các bệnh NKHHC ở trẻ dưới 5 tuổi còn chưa rõ ràng, cần có nghiên cứu nhiều hơn nữa để có kết luận cụ thể.

Từ thực tế này chúng tôi tiến hành đề tài nhằm mục tiêu sau đây: Đánh giá hiệu quả bổ sung vitamin $D$ với nhiểm khuân hô hấp câp tính trẻ dưới 5 tuôii tại huyện An Lão, Hải Phòng năm 2017.

\section{II. ĐỐI TƯỢNG VÀ PHƯƠNG PHÁP NGHIÊN CỨU}

2.1. Đối tượng, địa điểm và thời gian nghiên cứu:

- Gồm 164 trẻ dưới 5 tuổi được chia thành 2 nhóm can thiệp (NCT) và nhóm chứng (NC). Nhóm can thiệp là xã Trường Thọ và nhóm chứng là xã An Thắng.

Đây là những đối tượng đã tham gia nghiên cứu ở giai đoạn 1 .

Tiêu chuẩn lựa chọn: bệnh nhân đồng ý tham gia nghiên cứu, cam kết không uống bất cứ chế phẩm vitamin $D$ nào khác ngoài chế phẩm do nghiên cứu cung cấp.

Nghiên cứu tại 2 xã của huyện An Lão, Hải 
Phòng. Thời gian từ 12/2016 đến 12/2017.

\subsection{Phương pháp nghiên cứu}

2.2.1. Thiết kế nghiên cứu: Nghiên cứu can thiệp cộng đồng, so sánh trước sau có đối chứng.

\subsubsection{Cõ̃ mẫu/chọn mẫu}

Chúng tôi sử dụng công thức tính cỡ mẫu dựa trên đánh giá sự thay đổi nồng độ Vitamin $D$ sau can thiệp cho NCT và NC: cụ thể tính ra cỡ mẫu 82 trẻ cho 1 nhóm. Số trẻ ở mỗi nhóm được chọn theo phương pháp ngẫu nhiên hệ thống trên cơ sở những trẻ đang tham gia nghiên cứu ở điều tra ngang.

Bảng 2.1. Danh sách trẻ $0-<5$ tuổi của các xã được chọn vào nghiên cứu giai đoạn 2.

\begin{tabular}{|c|c|c|}
\hline$T \pi$ & Tên xã & Số trẻ 0-<5 tuối \\
\hline 1 & $\begin{array}{l}\text { Trường Tho } \\
\text { (NCT) }\end{array}$ & $\begin{array}{l}207 \text { (7 loại vì nồng độ } \\
\text { vitamin } \mathrm{D}<20 \mathrm{ng} / \mathrm{ml} \text { ) }\end{array}$ \\
\hline 2 & $\begin{array}{l}\text { An Thắng } \\
\text { (NC) }\end{array}$ & $\begin{array}{l}190 \text { (2 loại vì nồng đố } \\
\text { vitamin } \mathrm{D}<20 \mathrm{ng} / \mathrm{ml} \text { ) }\end{array}$ \\
\hline Tống & & 397 \\
\hline
\end{tabular}

Chúng tôi loại khỏi nghiên cứu 9 trẻ có nồng độ vitamin $D$ thấp $<20 \mathrm{ng} / \mathrm{ml}$ để điều trị thiếu vitamin $\mathrm{D}$ (xem bảng 2.1 ).

2.2.3. Tiến hành can thiệp

Nhóm can thiệp: Tất cả đối tượng được uống hàng ngày 1 giọt vitamin $D$ tương đương 500 IU có tên là Aquadertrim có bán trên thị trường Việt Nam. Thời gian uống 1 năm. Thời điểm bắt đầu uống sau điều tra ngang (T0). Trong quá trình uống vào tháng thứ 6 (T6) và tháng thứ (T12) là tháng kết thúc can thiệp trẻ đều được xét nghiệm nồng độ vitamin $D$, cân, đo, khám phát hiện bệnh nhiễm khuẩn hô hấp.

Nhóm chứng: Trẻ không được tác động gì, nhưng vẫn được theo dõi theo các thời điểm và làm các đánh giá giống nhóm can thiệp. Trẻ vẫn được hưởng các chương trình dành cho trẻ dưới 5 tuổi tại địa phương.

\subsubsection{Chỉ số và biến số}

- Tuổi, giới

- Chiều cao, cân nặng

- Nồng độ vitamin D

- Hiêuu quả cải thiện nồng độ vitamin D câp

- Hiệu quả cải thiện tỷ lệ nhiễm khuẩn hô hấp

2.2.5. Thu thập thông tin.Sau can thiệp vào tháng 12/2017, các thông tin cần thu thập gồm:

- Cân nặng, chiều cao, nồng độ vitamin D và tỷ lệ nhiễm khuẩn hô hấp cấp.

- Công cụ, trang thiết bị và điều tra viên giống như ở nghiên cứu ngang.

2.2.6. Xử lý số liệu

Số liệu thu được, được làm sạch và nhập vào phần mềm SPSS 20.0.

Tính giá trị trung bình, so sánh giá trị trung bình bằng paired samgples $T$ test, sự khác biệt có ý nghĩa khi $p<0,05$. Dùng $x^{2}$ test để so sánh 2 số \%, có sự khác biệt khi $p<0,05$.

\section{KẾT QUẢ NGHIÊN CỨU}

3.1. Thông tin về đối tượng tham gia nghiên cứu can thiệp

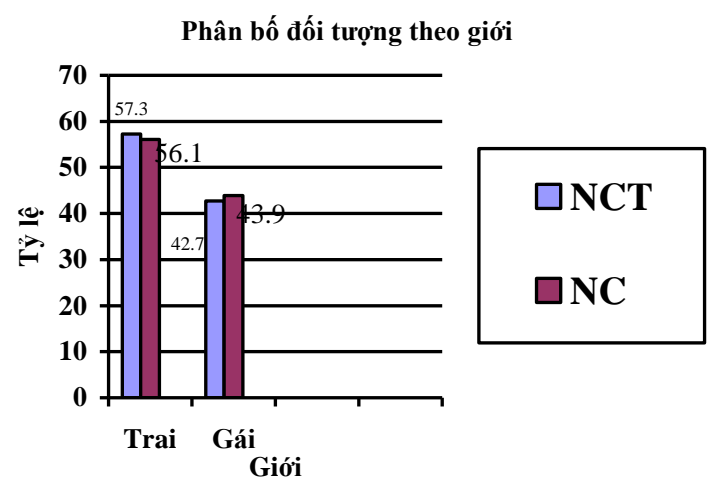

Hình 3.1. Phân bố đôi tượng can thiệp theo giới và theo địa điểm nghiên cứu $(n 1=n 2=82)$

Nhận xét. Ở xã can thiệp, trẻ trai nhiều hơn trẻ gái và ở xã chứng trẻ trẻ gái nhiều hơn trẻ trai, tuy nhiên sự khác nhau không có ý nghĩa thống kê với $p=0,875$.

Bảng 3.1. Phân bố đôi tượng can thiệp theo nhóm tuổi và theo xã

\begin{tabular}{|c|c|c|c|c|}
\hline $\begin{array}{c}\text { Nhóm } \\
\text { tuối } \\
\text { (tháng) }\end{array}$ & $\begin{array}{c}\text { NCT } \\
(\mathbf{n 1 , \% )}\end{array}$ & $\begin{array}{c}\text { NC } \\
(\mathbf{n 2} \mathbf{2} \%)\end{array}$ & Tổng & \multirow{2}{*}{$\mathbf{p}$} \\
\hline $0-<12$ & $3(42,9)$ & $4(57,1)$ & $7(4,3)$ & \\
\hline $12-<24$ & $12(35,5)$ & $22(64,7)$ & $34(20,7)$ & \\
\hline $24-<36$ & $23(53,5)$ & $20(46,5)$ & $43(26,2)$ & 0,35 \\
\hline $36-<48$ & $24(54,2)$ & $22(45,8)$ & $46(28,0)$ & \\
\hline $48-<60$ & $20(58,8)$ & $14(41,2)$ & $34(20,7)$ & \\
\hline Tống sốn & $\mathbf{8 2}$ & $\mathbf{8 2}$ & $\mathbf{1 6 4}$ & \\
\hline
\end{tabular}

Nhận xét. Nhìn cả 2 xã can thiệp và chứng chúng tôi thấy đối tượng tham gia nghiên cứu tập trung vào nhóm tuổi $12-<24$ đến $48-<60$ tháng với tỷ lệ lần lượt là $20,7 \%, 26,2 \%, 28,0 \%$ và $20,7 \%$. Nhóm $0-<12$ tháng chiếm tỷ lệ thấp nhất 4,3\%.

So nhóm tuổi theo xã can thiệp và xã chứng chúng tôi thây xã chứng có nhóm đối tượng 3,4 và 5 tuổi có số đối tượng nhiều hơn xã chứng nhưng ở nhóm 1 và 2 tuổi xã chứng lại có số đối tượng nhiều hơn xã can thiệp, nhưng khác biệt này không có ý nghĩa thống kê với $p=0,35$.

\subsection{Hiệu quả can thiệp bổ sung vitamin D}


VIETNAM MEDICAL JOURNAL N01 - SEPTEMBER - 2021

Bảng 3.2. Hiệu quả cải thiện nồng độ vitamin $D(\mathrm{ng} / \mathrm{ml}$ của nhóm can thiệp và nhóm chứng (n1=n2=82)

\begin{tabular}{|c|c|c|c|c|c|}
\hline Địa điểm & $\begin{array}{c}\text { Vitamin TB } \\
\text { ơ TO }\end{array}$ & $\begin{array}{c}\text { Vitamin D TB } \\
\text { ơ T6 }\end{array}$ & $\begin{array}{c}\text { Vitamin D TB ở } \\
\text { T12 }\end{array}$ & & $\mathbf{p}$ \\
\hline & $26,65 \pm 4,63^{*}$ & $30,88 \pm 8,59 * *$ & $32,19 \pm 4,72^{* * *}$ & & \\
\hline \multirow[t]{2}{*}{ NCT } & & $\begin{array}{c}\text { Vitamin D TB tăng } \\
\text { thêm (T0-6) }\end{array}$ & $\begin{array}{c}\text { Vitamin D TB tăng } \\
\text { thêm (T6-12) } \\
\end{array}$ & $\begin{array}{l}\text { Vitamin D TB tăng } \\
\text { thêm (T0-12) }\end{array}$ & \multirow{2}{*}{$\begin{aligned}(0,6) & =0,000 \\
(6-12) & =0,000 \\
(0,12) & =0,000\end{aligned}$} \\
\hline & & $4,23 \pm 3,96^{1}$ & $1,30 \pm 3,87^{2}$ & $5,54 \pm 0,09^{3}$ & \\
\hline Địa điếm & Vitamin TB ở T0 & \begin{tabular}{|l} 
Vitamin D TB ở T6 \\
\end{tabular} & Vitamin D TB ơ T12 & & $p$ \\
\hline \multirow{3}{*}{ NC } & $27,15 \pm 5,84^{*}$ & $26,88 \pm 6,37^{* *}$ & $28,71 \pm 6,94 * * *$ & & \multirow{3}{*}{$\begin{aligned}(0,6) & =0,77 \\
(6-12) & =0,121 \\
(0,12) & =0,100\end{aligned}$} \\
\hline & & $\begin{array}{c}\text { Vitamin D TB tăng } \\
\text { thêm }(T 0-6)\end{array}$ & \begin{tabular}{|c} 
Vitamin D TB tăng \\
thêm (T6-12)
\end{tabular} & $\begin{array}{l}\text { Vitamin D TB tăng } \\
\text { thêm (T0-12) }\end{array}$ & \\
\hline & & $0,27 \pm 0,17^{1}$ & $1,55 \pm 1,10^{2}$ & $1,38 \pm 1,16^{3}$ & \\
\hline $\mathrm{p}$ & $* 0,544$ & $* * 0,001$ & $* * * 0,000$ & & \\
\hline $\begin{array}{l}\text { Mức chênh } \\
\text { nhau }\end{array}$ & & $3,96 \pm 3,79^{1}$ & $0,25 \pm 2,77^{2}$ & $4,16 \pm 1,07^{3}$ & \\
\hline
\end{tabular}

Paired samples T-Test được sử dụng để so sánh nồng độ vitamin D TB của NCT và NC trước và sau can thiệp

*nồng độ vitamin D TB ở To; **nồng độ vitamin D TB ở T6; ***nồng độ vitamin D TB ở T12; 1 , 2,3nồng độ vitamin D TB chênh nhau ở NCT và NC theo thời điểm T0, 6 và 12 .

Nhận xét. Ở nhóm can thiệp, nồng độ vitamin D TB tăng từ $26,65 \pm 4,63 \mathrm{ng} / \mathrm{ml}$ lên $30,88 \pm 8,59 \mathrm{ng} / \mathrm{ml}$ tháng thứ 6 và $32,19 \pm 4,72$ $\mathrm{ng} / \mathrm{ml}$ ở T12. Sự khác biệt về nồng độ trung bình ở các thời điểm sau can thiệp có ý nghĩa thống kê với $p$ đều là 0,000 . Nồng độ vitamin $D$ TB tăng thêm từ 4,23 lên 5,54 ng/ml.

Ơ nhóm chứng nồng độ vitamin D TB tăng từ $27,15 \pm 5,84 \mathrm{ng} / \mathrm{ml}$ lên $26,88 \pm 6,37 \mathrm{ng} / \mathrm{ml}$ tháng 6 và $28,71 \pm 6,94 \mathrm{ng} / \mathrm{ml}$ tháng 12 những sự tăng này chưa đủ lớn tạo ra sự khác biệt với $\mathrm{p}$ lần lượt là $0,77,0,121$ và 0,100 . Nồng độ vitamin $D$ TB tăng thêm tăng từ 0,27 lên $1,38 \mathrm{ng} / \mathrm{ml}$ ở tháng 12. Có sự khác biệt lớn về tăng nồng độ vitamin D TB ở 2 xã vào tháng $6(30,88 \pm 8,59$ $\mathrm{ng} / \mathrm{ml}$ và $26,88 \pm 6,37 \mathrm{ng} / \mathrm{ml}, \mathrm{p}=0,001)$ và tháng thứ 12 là $32,19 \pm 4,72 \mathrm{ng} / \mathrm{ml}$ và $28,71 \pm 6,94$ $\mathrm{ng} / \mathrm{ml}$ và $\mathrm{p}=0,000$.

Nồng độ vitamin $\mathrm{D}$ cải thiện tốt hơn ở nhóm can thiệp vào tháng thứ 6 và 12 , trong khi đó không cải thiện ở nhóm chứng.

\subsection{Hiệu quả cải thiện tỷ lệ nhiễm khuẩn hô hấp}

Bảng 3.3. Hiệu quả cải thiện tỷ lệ nhiếm khuấn hô hấp ở xã can thiệp và xã chứng sau can thiệp $(n 1=n 2=82)$

\begin{tabular}{|c|c|c|c|c|c|}
\hline $\begin{array}{l}\text { Đia } \\
\text { điểm }\end{array}$ & $\begin{array}{l}\text { Tỷ lệ NKHH } \\
\text { ờ To }(n, \%)\end{array}$ & $\begin{array}{l}\text { Tỷ lệ NKHH } \\
\text { ở T6́ }(n, \%)\end{array}$ & $\begin{array}{l}\text { Tỷ lệ NKHH } \\
\text { ở T12 (n,\%) }\end{array}$ & & p \\
\hline \multirow{3}{*}{ NCT } & $35^{*} 47,2$ & $25 * * 30,5$ & $8 * * * \quad 9,8$ & & \multirow{3}{*}{$\begin{aligned}(0,6) & =0,105 \\
(6-12) & =0,0009 \\
(0,12) & =0,0002\end{aligned}$} \\
\hline & & $\begin{array}{c}\text { Tỷ lê NKHH giảm đi } \\
(\mathrm{T} 0-6)(\%)\end{array}$ & $\begin{array}{c}\text { Tỷ lệ NKHH giảm đi } \\
(\text { T6-12)(\%) }\end{array}$ & $\begin{array}{l}\text { Tỷ lê NKHH giảm } \\
\text { đi }(T 0-12)(\%)\end{array}$ & \\
\hline & & $12,2^{1}$ & $20,7^{2}$ & $37,4^{3}$ & \\
\hline Địa điểm & $\begin{array}{l}\text { Tỷ lê NKHH } \\
\text { ở Tó }(n, \%)\end{array}$ & $\begin{array}{l}\text { Tỷ lề NKHH } \\
\text { ớ T6́ }(n, \%)\end{array}$ & $\begin{array}{c}\text { Tỷ lệ NKHH ở T12 } \\
(n, \%)\end{array}$ & & $\mathrm{p}$ \\
\hline \multirow{3}{*}{ NC } & $29 * 35,4$ & $24 * * 29,3$ & $17 * * * \quad 20,7$ & & \multirow{3}{*}{$\begin{array}{c}(0,6)=0,403 \\
(6-12)=0,860 \\
(0,12)=0,086\end{array}$} \\
\hline & & $\begin{array}{l}\text { Tỷ lệ NKHH giảm đi } \\
(T 0-6)(\%)\end{array}$ & $\begin{array}{c}\text { Tỷ lệ NKHH giám đi } \\
\text { (T6-12) (\%) }\end{array}$ & $\begin{array}{l}\text { Tỷ lê NKHH giảm } \\
\text { đi (T0-12) (\%) }\end{array}$ & \\
\hline & & $6,1^{1}$ & $8,6^{2}$ & $14,7^{3}$ & \\
\hline$p$ & $* 0,337$ & $* * 0,864$ & $* * * 0,0206$ & & \\
\hline $\begin{array}{l}\text { Mức } \\
\text { chênh }\end{array}$ & & $6,1^{1}$ & $12,1^{2}$ & $22,7^{3}$ & \\
\hline
\end{tabular}

Chi square sử dụng để so sánh 2 tỷ lệ, sự khác biệt khi $p<0,05$.

*tỷ lệ NKHH ở To; **tỷ lệ NKHH ở T6; ***tỷ lệ NKHH ở T12; 1, 2,3tỷ lệ NKHH chênh nhau ở NCT và NC theo thời điểm T0, 6 và 12 .

Nhận xét. Ở nhóm can thiệp tỷ lệ nhiễm

khuẩn hô hấp giảm từ T0 đến T6 không có ý nghĩa thống kê với $p=0,105$, từ T6 đến T12 có ý nghĩa thống kê với $p=0,0009$, tỷ lệ nhiễm khuẩn hô hấp cấp giảm từ T0 đến T12 là 37,4\% và sự khác biệt có ý nghĩa thống kê với $p=0,0002$.

ở nhóm chứng tỷ lệ nhiễm khuẩn hô hấp cấp 
giảm không rõ rệt, sự khác biệt này đều không có ý nghĩa thông kê với $p$ lần lượt là $0,403,0,86$ và 0,086 .

Tỷ lệ nhiễm khuẩn hô hấp ở T0 không có sự khác nhau giữa 2 xã $(p=0,337)$, ở T6 $p=864$ nhưng ở T12 tỷ lệ NKHH ở nhóm can thiệp thấp hơn rất nhiều so với nhóm chứng và $p=0,0206$.

\section{BÀN LUẬN}

4.1. Hiệu quả cải thiện nông độ vitamin. Bảng 3.2 cho thấy sau hiệu quả can thiệp nâng nồng độ vitamin D TB của NCT và NC. Ở NCT nồng độ vitamin $\mathrm{D}$ TB trước can thiệp (T0) là $26,65 \pm 4,63 \mathrm{ng} / \mathrm{ml}$ tăng lên $30,88 \pm 8,59 \mathrm{ng} / \mathrm{ml}$ (T6) và $32,19 \pm 4,72 \mathrm{ng} / \mathrm{ml}$ ở T12. Sự khác biệt về nồng độ ở các thời điểm sau can thiệp so với trước can thiệp đều có ý nghĩa thống kê:: $p(0,6)$, $\mathrm{p}(6-12), \mathrm{p}(0,12)$ đều là 0,000 . Tính mức tăng nồng độ vitamin $B$ TB ở $T(0-6)$ là 4,23 $\pm 3,96$ $\mathrm{ng} / \mathrm{ml}$, ở $\mathrm{T}(6-12)$ là $1,30 \pm 3,87 \mathrm{ng} / \mathrm{ml}$ và ở $\mathrm{T}(0-$ 12) là $5,54 \pm 0,09 \mathrm{ng} / \mathrm{ml}$.

Ớ NC, nồng độ vitamin D TB trước can thiệp là $27,15 \pm 5,84 \mathrm{ng} / \mathrm{ml}$, ở T6 nồng độ vitamin $D$ TB là $26,88 \pm 6,37 \mathrm{ng} / \mathrm{ml}$ và ở $\mathrm{T} 12$ nồng độ vitamin D TB là $28,71 \pm 6,94 \mathrm{ng} / \mathrm{ml}$. Mức tăng nồng độ vitamin $D$ TB thời điểm $T(0,6)$ là $0,27 \pm$ $0,17 \mathrm{ng} / \mathrm{ml}$, thời điểm $\mathrm{T}(6-12)$ là $1,55 \pm$ $1,10 \mathrm{ng} / \mathrm{ml}$ và thời điểm $\mathrm{T}(0,12)$ là $1,38 \mathrm{ng} / \mathrm{ml}$.

Khi so sánh nồng độ vitamin D TB ở T0, T6 và T12 chúng tôi thây chỉ nồng độ vitamin $D$ TB của NCT và NC ở T6 và T12 có sự khác nhau với $p$ lân lượt là 0,001 và 0,000 . Ở $T 12$ nồng độ vitamin $D$ TB của NCT cao nhiêuu hơn NC là 4,16ng/ml.

Theo Nguyễn Xuân Hùng [1] tỷ lệ thiếu hụt Vitamin D ở NCT là 20,7\%, sự khác biệt tỷ lệ trước can thiệp $(38,9 \%)$ và sau can thiệp $(18,2 \%)$ có ý nghĩa thống kê. Hiệu quả can thiệp đạt $53,21 \%(p<0,05)$. Sự cải thiện không đáng kể về tỷ lệ thiếu hụt Vitamin $D$ ở NC trước - sau can thiệp ( $46,4 \%$ so với $44,2 \%$ theo thứ tự và $\mathrm{p}>0,05)$. So sánh tỷ lệ thiếu hụt Vitamin $D$ trước can thiệp của 2 nhóm tác giả không thây có sự khác biệt $p>0,05(0,368)$ nhưng so sánh tỷ lệ thiếu hụt sau can thiệp của 2 nhóm có sự khác biệt $(18,2 \%$ ở NCT và $44,2 \%$ ở nhóm NC và $p<0,01)$.

Tác giả Heike $A$ Bischoff Ferrari và CS năm 2006 bổ sung một liều cho tất cả người lớn $>1000$ IU Vitamin D ngày để có thể đạt được trên $50 \%$ dân số có nồng độ Vitamin $D$ trên 75 nmol/L [7]. Nghiên cứu của Steven Abrams năm 2013 đã lựa chọn liều bổ sung 1000 IU Vitamin D ngày cho mọi nhóm tuổi, sau 8 tuần bổ sung Vitamin $D$ đã tìm thây mối quan hệ có ý nghĩa giữa nồng độ $1,25(\mathrm{OH})_{2}$ Vitamin $\mathrm{D}$ và hấp thu canxi. Theo tác giả Holick và CS nghiên cứu năm 2008, chỉ khi liều Vitamin D được tăng lên đến 800 IUngày trong 5 tháng thì nồng độ 25 $(\mathrm{OH})_{2}$ VitaminD mới tăng lên và duy trì trên 75 $\mathrm{nmol} / \mathrm{L}$ hay $30 \mathrm{ng} / \mathrm{mL}$ [8]. Nghiên cứu của chúng tôi áp dụng với liều bố sung 200.000 IU trong 12 tháng đã cải thiện tỷ lệ thiếu hụt Vitamin $D$ ở 68,64\% đối tượng can thiệp.

4.2. Hiệu quả cải thiện tỷ lệ nhiễm khuẩn hô hấp. Bảng 3.3 cho thấy hiệu quả cải thiện bệnh NKHH sau can thiệp ở NCT và NC. Ở NCT, chúng tôi thây tỷ lệ NKHH trước can thiệp TO là $47,2 \%$, giảm xuống $30,5 \%$ ở $\mathrm{T} 6$ và $9,8 \%$ ở $\mathrm{T} 12$. Tỳ lệ giảm từ T0-6 là 12,2\% tuy nhiên sự khác biệt này không có ý nghĩa thống kê $(p=0,105)$. Tỷ lệ giảm $T(6,12)$ là $20,7 \%$ và sự khác biệt này có ý nghĩa thống kê với $p=0,000$. Tỷ lệ NKHH giảm $\mathrm{T}(0-12)$ là $37,4 \%$ và tất nhiên sự khác biệt này rất có ý nghĩa thống kê với $p=0,000$.

Ở nhóm chứng, tỷ lệ NKHH giảm từ 35,4\% ở T0 xuống 29,3\% T6 nhưng sự khác biệt không có ý nghĩa thống kê $(p=0,403)$, từ $29,5 \%$ ở T6 xuống 20,7\% ở T12 nhưng sự khác biệt cũng không có ý nghĩa thống kê $(p=0,860)$. Từ T0 xuống T12 tỷ lệ NKHH giảm chưa đủ mạnh để có sự khác biệt với $p=0,086$.

Theo chiều ngang tỷ lệ NKHH ở thời điểm TO, T6 của NCT và NC cũng không có sự khác biệt $p$ lần lượt là $0,337,0,864$. Tuy nhiên ở thời điểm T12, tỷ lệ NKHH ở NCT giảm nhiều hơn NC và sự khác biệt về tỷ lệ này có ý nghĩa thống kê với $\mathrm{p}=0,0206$. Đến T12 tỷ lệ NKHH của NCT giảm hơn NC là 22,7\%.

Kết quả nghiên cứu của chúng tôi phù hợp với các nghiên cứu trong và ngoài nước. Trước hết kết quả thử nghiệm ngẫu nhiên có đối chứng cho thây hiệu quả bổ sung vitamin $D$ làm giảm các bệnh NKHH. Nghiên cứu của Mark Loeb và CS ở trẻ em và thiếu niên Việt Nam bổ sung 14.000 đơn vị vitamin $\mathrm{D}$ hàng tuần trong 8 cho 650 trẻ 3-17 tuổi và bổ sung giả dược cho 650 trẻ khác cùng tuổi, trong cùng thời gian cho thây hiệu quả giảm nhiễm khuẩn không do siêu vi khuẩn ở nhóm bổ sung vitamin $D$ rất rõ ràng với HR là 0,81 .

Thử nghiệm ngẫu nhiên đối chứng mù kép của Semira Manaseki-Holland và CS để xác định việc bổ sung 100.000 đơn vị vitamin $D D_{3}$ kết hợp với kháng sinh có làm giảm thời gian bệnh của trẻ mắc viêm phổi và giảm nguy cơ tái phát bệnh. Nhóm bổ sung vitamin $D$ gồm 224 trẻ 1-36 tháng, nhóm giả dược gồm 229 trẻ. Kết quả cho thấy bổ sung vitamin $D$ làm giảm tái phát bệnh trong vòng 90 ngày sau bổ sung $(\mathrm{HR}=0,71)$. 
Nghiên cứu thử nghiệm đối chứng mù kép khác của Seiji Arihiro và CS trên 223 trẻ mắc bệnh đường ruột được chia thành 2 nhóm, nhóm bổ sung vitamin $D$ và nhóm bổ sung giả dược ( $n=108$ và $n=105$ theo thứ tự). Đối tượng nhận 500 đơn vị vitamin $D$ hàng ngày. Kết quả cho thấy nhóm bổ sung vitamin $\mathrm{D}$ có tỷ lệ mắc $\mathrm{NKHH}$ trên thấp hơn nhiều nhóm dùng giả dược ( $R R=0,59)$.

Rashmi Ranjan Das và CS nghiên cứu gộp 32 nghiên cứu để so sánh điều trị viêm phổi bằng vitamin $D$ và giả dược. Liều vitamin $D$ được sử dụng từ 1000 đơn vị đến 100.000 đơn vị cho trẻ dưới 5 tuổi, cách thức cung cấp vitamin $D$ có thể là liều đơn, hay 5 liều trong vòng 5 ngày, thời gian can thiệp là 1 năm. Kết quả không như trông đợi, việc sử dụng vitamin $D$ đường uống này không giúp nhiều cho trẻ dưới 5 tuổi mắc viêm phổi cấp.

\section{KẾT LUÂN}

Sau can thiệp nồng độ vitamin $D$ trung bình của nhóm can thiệp tăng thêm $5,54 \mathrm{ng} / \mathrm{ml}$ so với của $\mathrm{NC}$ là $1,38 \mathrm{ng} / \mathrm{ml}$, nồng độ vitamin $\mathrm{D}$ trung bình tăng thêm là $4,16 \mathrm{ng} / \mathrm{ml}$.

Can thiệp vitamin $D$ đã làm giảm tỷ lệ nhiễm khuẩn hô hấp ở nhóm can thiệp được 37,4\% so với nhóm chứng là $14,7 \%$, tỷ lệ nhiếm khuẩn hô hấp của nhóm can thiệp giảm hơn nhóm chứng là $22,7 \%$.

\section{TÀI LIỆ THAM KHẢO}

1. Nguyễn Xuân Hùng (2020), Thực trang suy dinh dưỡng thấp còi và hiệu quả can thiệp ở trẻ 12 đến
36 tháng tuổi tại huyện Kim Động, tỉnh Hưng Yên năm 2017", Luận án tiến sỹ Y học, Trường đại học Y Dược Hải Phòng.

2. Trân Quy. (2013), "Nhiễm khuẩn hô hấp cấp tính", Bài giảng nhi khoa tập 1 - Nhà xuất bản y học Hà Nội, trang 380-389.

3. Adebola E. Orimadegun et al (2020), "A systematic review and meta-analysis of sex defferences in morbidity and mortality of acute lower respiratory tract infections among african children", J Pediatr Rev, 8(2):65-78. doi:10.32598/jpr.8.2.65.

4. David A McAllister et al (2019), "Global, regional, and national estimates of pneumonia morbidity and mortality in children younger than 5 years between 2000 and 2015: a systematic analysis", Lancet Glob Health, 7(1):e47e57.doi:10.1016/S2214-109X(18)304408-X.

5. Giuseppe Saggesse et al (2018), "Vitamin D in pediatric age: consensus of the Italian Pediatric Society and the Italian Society of Preventive and social Pediatric, jointly with the Italian Federation of Pediatricians", Ital K Padiatr, 44:51. doi:10.1186/s13052-018-0488-7.

6. Giustina A và CS (2020), "Consensus statement from $2^{\text {nd }}$ International conference on controversies in vitamin D", Rev Endocr Metab Disord, 21(1):89116. doi: $10.1007 / \mathrm{s} 11154-019=09532-w$.

7. Heike A Bischoff - Ferrari et al (2006) "Estimation of optimal serum concentrations of 25 - hydroxyvitamin D for multiple health outcomes", Am J Clin Nutr. 84 (1): 18 - 28.

8. Holick F Michael (2007), "The vitamin D deficiency pandemic: Approach for diagnosis, treatment and prevention", Rev Endocr Metab Disord, 18(2):153-165. doi: $10.1007 / \mathrm{s} 11154-017$ 9424-1.

9. Holick MF and Tai C Chen (2008), "Vitamin D deficiency: a worldwide problem with health consequences", Am J Clin Nutr. 87 (4): 1080S - 1086S.

\section{NHÂN 1 TRƯờ'NG HỢP THAI NGOÀI Ý MUỒN TRONG KHI SỬ DỤNG QUE CẤY TRÁNH THAI IMPLANON NXT®}

\section{Nguyễn Ngọc Phương ${ }^{1}$, Hà Duy Tiến ${ }^{1}$, Nguyễn Thị Hồng Nhung ${ }^{1}$}

\section{TÓM TẮT}

Implanon $®$ là một nang chứa progestin tổng hợp (etonogestrel), được cấy dưới da với tác dụng tránh thai lâu dài có hồi phục. Trong hơn 10 năm có mặt tại thi trường Viêt Nam, Implanonß đang dân trở nên phổ biến vì tính tiện lợi và hiệu quả tránh thai rất cao. Các trường hợp mang thai ngoài ý muốn với que cây

${ }^{1}$ Bệnh viện Phụ Sản Trung Uơng

Chịu trách nhiệm chính: Nguyễn Ngọc Phương

Email: pika.hmu@gmail.com

Ngày nhận bài: 24.6.2021

Ngày phản biên khoa họ: 17.8.2021

Ngày duyệt bài: 25.8.2021 tránh thai etonogestrel là rất hiếm. Chúng tôi báo cáo 1 trường hợp có thai trong buồng tử cung trong khi đang tránh thai bằng que cấy Implanon NXTß. Bênh nhân 27 tuổi PARA 1001, cây que tránh thai từ tháng 4/2017. Sau cấy 8 tháng, bênh nhân được chẩn đoán lao phổi và điêu trị theo phác đồ 2RHZE/4RHE. 6 tháng sau khi bắt đâu điều trị, bệnh nhân phát hiện có thai 18 tuần. Que cấy vẫn nằm đúng vị trí và được tháo toàn ven sau đó 1 tuần. Bênh nhân tiếp tục theo dõi thai, đẻ thường đủ tháng với kết quả thăm khám sơ sinh bình thường. Qua đó minh họa như y văn đã đề cập, thuốc chống lao (với tác dụng cảm ứng enzym ở gan) có thể làm giảm tác dụng tránh thai của Implanon $\AA$.

Tư khóa: Thai ngoài ý muốn, que cấy tránh thai, Implanon, thuốc chống lao. 